\title{
High-intensity interval training in cardiac resynchronization therapy: a randomized control trial
}

\author{
Helena Santa-Clara ${ }^{1} \cdot$ Ana Abreu $^{2} \cdot$ Xavier Melo $^{1,3}\left(\right.$ Vanessa Santos $^{1} \cdot$ Pedro Cunha $^{2} \cdot$ Mário Oliveira $^{2} \cdot$ Rita Pinto $^{1}$. \\ Miguel Mota Carmo ${ }^{2,4} \cdot$ Bo Fernhall $^{5}$
}

Received: 19 March 2018 / Accepted: 23 August 2018 / Published online: 23 May 2019

○) Springer-Verlag GmbH Germany, part of Springer Nature 2019

\begin{abstract}
Aims To determine the effects of high-intensity interval training (HIIT) following cardiac resynchronization therapy (CRT) implantation in patients with chronic heart failure (CHF), on noninvasive estimates of systolic ventricular function, exercise performance, severity of symptoms and quality of life.

Methods Cardiopulmonary exercise testing, resting transthoracic echocardiogram and health-related quality of life assessment were obtained before and at 6 months after CRT implantation in 37 patients with moderate-to-severe CHF. Patients were randomized after CRT to either a 24-week HIIT group (90-95\% peak heart rate, 2 days per week) or to a usual care group $(\mathrm{CON})$. Mixed design $2 \times 2$ repeated measures ANOVA were used to test for differences within and in-between groups. Results Improvements in health-related quality of life (HIIT $=98.54 \%, \mathrm{CON}=123.47 \%)$, NYHA class (HIIT $=43.44 \%$, $\mathrm{CON}=38.30 \%)$ HR recovery at minute $1(\mathrm{HIIT}=32.32 \%, \mathrm{CON}=42.94 \%)$, pulse pressure at peak effort $(\mathrm{HIIT}=14.06 \%$, $\mathrm{CON}=9.52 \%, \mathrm{LVEF}(\mathrm{HIIT}=42.17 \%, \mathrm{CON}=51.10 \%)$ and $\mathrm{LV}$ Mass $(\mathrm{HIIT}=13.26 \%, \mathrm{CON}=11.88 \%)$ were similar in both groups $(p>0.05)$. Significant increases in CPET duration in the HIIT group $(25.94 \%)$, and increases in peak $\mathrm{VO}_{2}$ $(\mathrm{HIIT}=8.64 \%, \mathrm{CON}=4.85 \%)$ and percent-predicted $\mathrm{VO}_{2}(\mathrm{HIIT}=10.57 \%, \mathrm{CON}=4.26 \%)$ in both groups, were observed in the intention-to-treat analysis.

Conclusion Six months of HIIT in patients in CRT did not further improved indices of functional capacity and health-related quality of life, and LV structure and function, compared to CRT alone. However, HIIT led to further improvements in exercise performance. It remains unclear whether HIIT benefits patients in CRT to a similar degree as more conventional forms of exercise training previously shown to maximize benefits in CRT.
\end{abstract}

Clinical trial registration http://www.clinicaltrials.gov. Unique identifier: NCT02413151.

Keywords Exercise capacity $\cdot$ Chronic heart failure $\cdot$ Reduced ejection fraction $\cdot$ Exercise training

\begin{tabular}{l} 
Communicated by Keith Phillip George. \\
\hline Electronic supplementary material The online version of this \\
article (https://doi.org/10.1007/s00421-019-04165-y) contains \\
supplementary material, which is available to authorized users. \\
\hline $\begin{array}{l}\text { Xavier Melo } \\
\text { xaviermelo@ fmh.ulisboa.pt }\end{array}$ \\
Faculdade de Motricidade Humana, CIPER, Centro \\
Interdisciplinar de Estudo da Performance Humana, \\
Universidade de Lisboa, Sala 8, Pavilhão Lord, Estrada da \\
Costa, Cruz Quebrada, 1499-002 Lisbon, Portugal \\
Departamento de Cardiologia, Centro Hospitalar de Lisboa \\
Central, Hospital Santa-Marta, Rua de Santa Marta 50, \\
1169-024 Lisbon, Portugal
\end{tabular}

Abbreviations
CHF
CON
CPET

CRT

3 GCP Lab, Praça Ginásio Clube Português n.1, Ginásio Clube Português, 1250-111 Lisbon, Portugal

4 Faculdade de Ciências Médicas, CEDOC, Centro de Estudos de Doenças Crónicas, Universidade Nova, Campo Mártires da Pátria, 130, 1169-056 Lisbon, Portugal

5 Integrative Physiology Laboratory, College of Applied Health Sciences, University of Illinois at Chicago, 808 South Wood Street CMET 169, MC 518, Chicago, IL 60612, USA 


\begin{tabular}{|c|c|}
\hline HIIT & High-intensity interval training \\
\hline HR & Heart rate \\
\hline HR recovery $1 \mathrm{~min}$ & $\begin{array}{l}\text { Heart rate recovery at } 1 \text { min after } \\
\text { CPET }\end{array}$ \\
\hline HR recovery $3 \mathrm{~min}$ & $\begin{array}{l}\text { Heart rate recovery at } 3 \mathrm{~min} \text { after } \\
\text { CPET }\end{array}$ \\
\hline LV & Left ventricular \\
\hline LVEF & Left ventricular ejection fraction \\
\hline LV mass & Left ventricular mass \\
\hline LV EDV & Left ventricular end-diastolic volume \\
\hline LV ESV & Left ventricular end-systolic volume \\
\hline NYHA & $\begin{array}{l}\text { New York Heart Association Func- } \\
\text { tional Scale }\end{array}$ \\
\hline Peak PP & $\begin{array}{l}\text { Pulse pressure at peak effort during } \\
\text { cardiopulmonary exercise testing }\end{array}$ \\
\hline Peak RPP & $\begin{array}{l}\text { Rate pressure product at peak effort } \\
\text { during cardiopulmonary exercise } \\
\text { testing }\end{array}$ \\
\hline Peak HR & $\begin{array}{l}\text { Heart rate at peak effort during car- } \\
\text { diopulmonary exercise testing }\end{array}$ \\
\hline Peak $\mathrm{VO}_{2}$ & $\begin{array}{l}\text { Oxygen consumption at peak effort } \\
\text { during cardiopulmonary exercise } \\
\text { testing }\end{array}$ \\
\hline RER & Respiratory exchange ratio \\
\hline
\end{tabular}

\section{Introduction}

Cardiac resynchronization therapy (CRT) is recommended to reduce mortality and morbidity in patients with chronic heart failure (CHF) classified as New York Heart Association (NYHA) functional class III-IV. These patients are symptomatic despite optimal medical therapy with a reduced left ventricular (LV) ejection fraction (LVEF) and prolonged QRS. CRT has been shown to improve prognosis (Cleland et al. 2005) leading to reverse ventricular remodeling with a reduction in LV size, improvement in the LVEF and reductions in systolic LV volume (Santos et al. 2015; Brignole et al. 2013). However, $20-30 \%$ of patients show no or only minor clinical or echocardiographic improvements (Abraham et al. 2002). It is well accepted that exercise training is beneficial for patients with CHF producing improvements in peak oxygen consumption $\left(\mathrm{VO}_{2}\right)$, hemodynamics and healthrelated quality of life (Keteyian et al. 2010; Ellingsen et al. 2017). The Heart Failure: A Controlled Trial Investigating Outcomes of Exercise Training (HF-ACTION) trial has recently shown such improvements extend to patients with CHF classified as NYHA III-IV with and without pacing devices (Zeitler et al. 2015). Patients suitable for CRT are of a comparable functional status to those in the HF-ACTION trial, but the combination of exercise training and CRT has not been well-investigated. All four studies specifically designed to evaluate the effect of exercise training following
CRT concluded that exercise training maximizes benefits in peak $\mathrm{VO}_{2}$ (Patwala et al. 2009; Belardinelli et al. 2006; Conraads et al. 2007; Smolis-Bakk et al. 2015). However, the effect on NYHA classification, LV volumes and LVEF is not clear as abnormalities in LV systolic function were not associated with exercise capacity in patients referred to an exercise echocardiogram (Grewal et al. 2009). Furthermore, these studies initiated the exercise program 3 months after CRT, used short-term exercise training (2-4 months), and did not always describe the exercise load used in sufficient detail (Patwala et al. 2009; Belardinelli et al. 2006; Conraads et al. 2007; Smolis-Bąk et al. 2015). Exercise intensity is also an important factor for cardiovascular function and prognosis in patients with CHF and reduced LVEF (Hambrecht et al. 2000). Compared with traditional moderateintensity continuous training, emerging evidence indicates that HIIT provides equivalent if not indeed superior metabolic, cardiac, and systemic vascular adaptations, thereby supporting more time-, retention- and physiological-efficient approaches to optimize metabolic and cardiovascular health (Guiraud et al. 2012; Wisloff et al. 2007; Wisløff et al. 2009; Weston et al. 2014). However, these health benefits have not yet been examined in patients in CRT. This knowledge would inform exercise prescription guidelines and allow exploration of alternative approaches to assess the health benefits that exercise provides for patients in CRT.

Therefore, we conducted a randomized controlled trial (RCT) in patients with CHF to determine the effects of a 6-month HIIT program initiated soon after CRT implantation (2-4 weeks) on selected noninvasive estimates of systolic function, exercise performance, severity of symptoms and health-related quality of life.

\section{Methods}

\section{Study population and randomization procedure}

This study is a randomized, single-center control trial conducted from 2012 to 2015. One-hundred twenty-one patients, from Hospital Santa Marta, with CHF and referred for CRT were eligible for the study (Fig. 1). Patients were randomized and stratified (by gender, age and etiology) following CRT. The randomization code was developed with a computer random-number generator to select random permuted blocks. Fifty-eight patients were not randomized either because they declined to participate in the study or as a result of clinical changes during the CRT implantation. The remaining 63 patients with moderate-to-severe CHF (NYHA class II-IV who were under optimal medical therapy with QRS $>120 \mathrm{~ms}$ ) were randomized to HIIT (HIIT, $n=34)$ or to the usual care group (CON, $n=29)$. One patient from the HIIT group died during the study and 20 patients 


\section{Enrollment}

$$
\text { Assessed for eligibility }(n=121)
$$

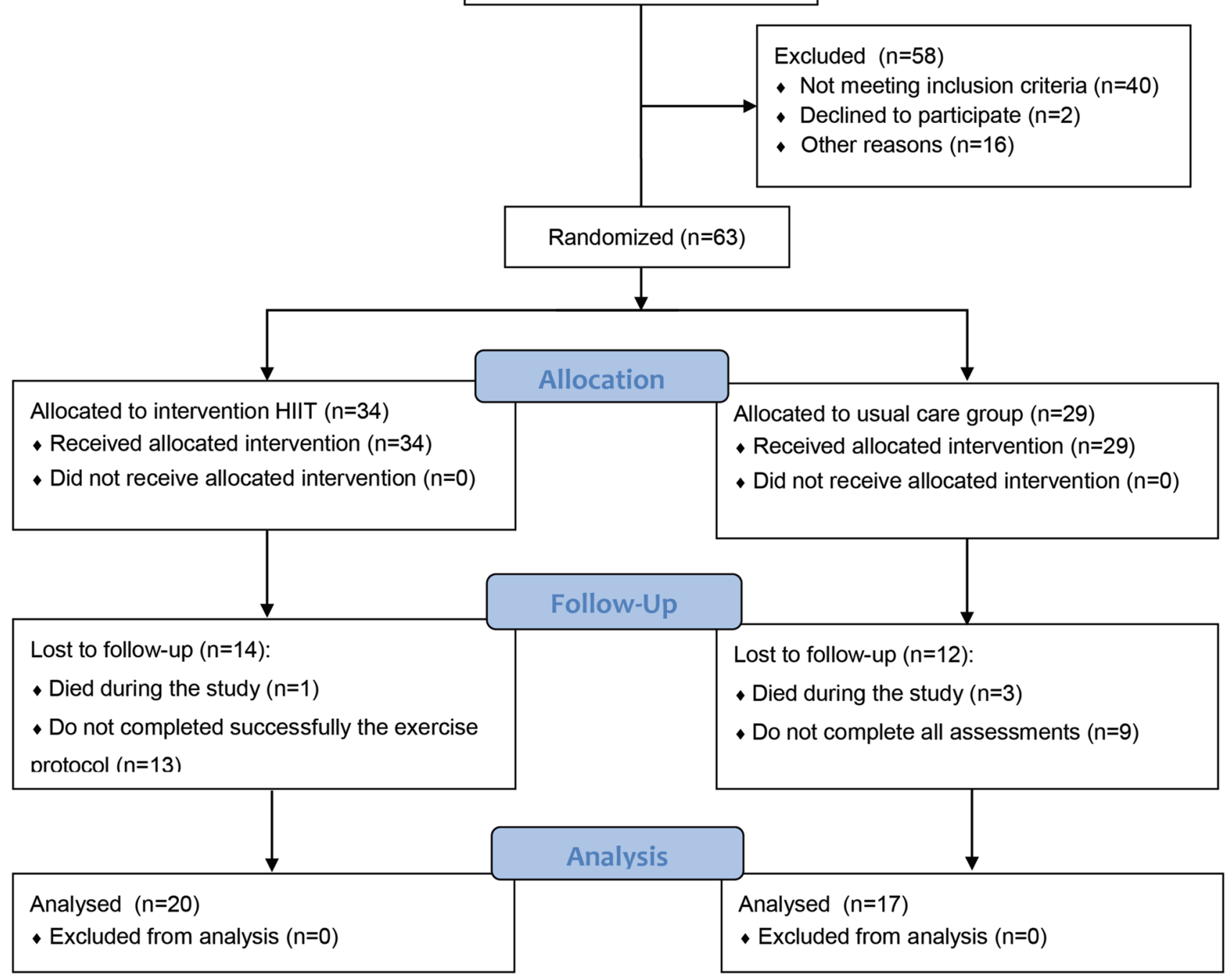

Fig. 1 Flow diagram of the study

successfully completed the exercise protocol with attendance above $80 \%$ during the 48 sessions including all evaluation visits. Three of the 29 control patients died during the study and 9 did not complete assessments (Supplement 1). Therefore, 37 patients (HIIT, $n=20$; CON, $n=17$ ) completed the study. Exclusion criteria were: geographical distance from the hospital center $(>20 \mathrm{~km})$, incapacitating orthopedic, neurologic, or other limitations that limiting exercise, declining to participate in the study, inability to sign the informed consent, previous treatment with an intravenous inotropic agent within the 30 days prior to implantation, or unstable angina pectoris. Optimal medical therapy for CHF was considered to include a diuretic, an angiotensin-converting enzyme inhibitor or an angiotensin receptor blocker and a beta-blocker, as recommended (Ponikowski et al. 2016).
All patients underwent cardiopulmonary exercise testing, a resting transthoracic echocardiogram and healthrelated quality of life assessment. All measurements were performed before CRT implantation and repeated 6 months after implantation. The CON group was given no specific advice on exercise training and underwent no supervised training. No change in cardiac medication occurred as part of the study protocol. The study was performed according to the Helsinki declaration, approved by the hospital medical ethics research committee and registered in Clinicaltrials.gov (NCT02413151). Written informed consent was obtained from all patients. 


\section{Cardiopulmonary exercise testing}

A symptom-limited incremental cardiopulmonary exercise testing (CPET) was performed on a treadmill (Bruce protocol) with breath-by-breath gas exchange measurements (Innocor $^{\circledR}$, Innovision, Cardiosolutions) and online realtime calculation of $\mathrm{VO}_{2}, \mathrm{CO}_{2 \text { peak }}$ production and respiratory exchange ratio (RER). Subjects were tested $2 \mathrm{~h}$ post-prandial and under the regular medication. A 12-lead electrocardiogram was recorded continuously, and blood pressure was measured by auscultation using an aneroid sphygmomanometer (at rest, at the end of each stage and every min after peak effort). The pulse pressure (PP) and the rate pressure product (RPP) at rest and at peak effort were calculated. Subjects were encouraged to exercise until exhaustion, as defined by the inability to keep up with the treadmill speed, by leg fatigue or dyspnea, and RER values $>1.1$, unless clinical criteria for earlier test termination were observed. Peak $\mathrm{VO}_{2}$ was considered the highest attained $\mathrm{VO}_{2}$ during the final $30 \mathrm{~s}$ of exercise (10 s average). Percent-predicted peak $\mathrm{VO}_{2}$ was calculated according to normative values proposed by Wasserman et al. (2012) (1 of 6 equations according to sex and bodyweight). Peak $\mathrm{O}_{2}$ pulse was calculated as the ratio of peak $\mathrm{VO}_{2}$ to peak heart rate, and the myocardial workload at peak effort was calculated as the rate pressure product.

\section{Echocardiography parameters}

Echocardiography was performed according to the guidelines of the American and European guidelines for echocardiographic examination (Evangelista et al. 2008; Lang et al. 2015). Resting M-mode echocardiographic measurements of LV end-diastolic and end-systolic diameter were performed from the parasternal long axis. LVEF and volumes (LVESV and LVEDV) were quantified according to the modified Simpson's rule (Schiller et al. 1989). Septal and posterior wall thickness were assessed by using linear measurements in parasternal long-axis view images at the level of LV minor axis, as previously suggested (Lang et al. 2015). LV mass was calculated using the Devereux formula (Devereux et al. 1986).

\section{Health-related quality of life}

Health-related quality of life was assessed using a validated Portuguese version of the HeartQoL, a 14-item self-administered questionnaire enabling respondents to recall how much their heart problem bothered them during the past 4 weeks, which has been validated in patients with CHF (Oldridge et al. 2014). The HeartQoL is scored on a four-point Likert scale (0-3) with higher scores representing better healthrelated quality of life. A global, physical and emotional HeartQoL score can be calculated (Oldridge et al. 2014).

\section{Exercise training}

The exercise sessions were supervised, hospital-based, electrocardiogram monitored and implemented twice a week, each for $60 \mathrm{~min}$, on non-consecutive days for 6 months (48 sessions). During the first month, each interval training and active pause was increased by $30 \mathrm{~s}$ on a weekly basis, until accomplishing the 4 min work with 3 min of active rest. Every session included a 10-min warm up and a 5- to 7-min cooldown. Starting from the second month, the HIIT consisted of 4 interval training periods (high intensity: 90-95\% of maximal heart rate if below the device threshold) with 3 lower-intensity active periods (moderate intensity: $60-70 \%$ of maximal heart rate if below the device threshold) between interval training periods (Wisloff et al. 2007). This HIIT regime had its effects compared and quantified against moderate-intensity continuous training in improving peak $\mathrm{VO}_{2}$ in patients with lifestyle-induced chronic diseases (Weston et al. 2014). The results revealed this HIIT regime induced greater reductions in blood pressure, improved blood glucose control, and increased aerobic capacity to a greater extent than did exercise conducted according to traditional guidelines. Furthermore, no increase in adverse events was reported with HIIT.

\section{Statistical analysis}

Variables were examined for normality, skewness, and kurtosis by performing the Shapiro-Wilk test of normality, visual inspection of normal quantile and histogram plots, and kurtosis and skewness summary statistics. Variables with a skewed distribution were log transformed for parametric statistical analyses.

Differences between groups at baseline and post-intervention, changes over time within each group and any interaction effect were assessed by mixed designed two-way repeated measures analysis of variance (ANOVA). Proportions were compared using Chi squared test.

Since this study was designed as an efficacy study, we focused initially on a per-protocol analyses, which included the patients in CRT that successfully completed the exercise protocol with attendance rates superior to $80 \%$. Next, we performed an intention-to-treat analysis using all participants that were randomized.

Statistical significance level was set at $p<0.05$ for all tests. The statistical analyses were computed and analyzed using the SPSS Statistics 24.0 (SPSS Inc., Chicago, IL, USA).

\section{Results}

Baseline characteristics of the 37 patients in CRT who met the per-protocol criteria are displayed in Table 1. Healthrelated quality of life, functional class, exercise 
performance and echocardiographic parameters are summarized in Table 2 for patients in CRT who met the perprotocol criteria, and in Supplement 2 for all patients in CRT as randomized.

\section{Functional capacity and health-related quality of life}

No significant differences were found between the HIIT and CON groups in functional capacity scale or health-related quality of life at baseline.

Health-related quality of life increased (HIIT $=98.5 \%$, $\left.\mathrm{CON}=123.5 \% ; p<0.001 ; \eta^{2}=0.535\right)$ and NYHA score decreased similarly in both groups (HIIT $=43.4 \%$, $\mathrm{CON}=38.3 \% ; p<0.001 ; \eta^{2}=0.623$; Table 2). The rate of clinical responders (sustained improvement $\mathrm{LVEF} \geq 15 \%$ ) in the HIIT group was $83.9 \%$ and in the CON group was $73.9 \%(p=0.371)$.

Similar results were observed in the intention-to-treat analysis (Supplement 3).

\section{Exercise performance}

No significant differences were found between the HIIT and $\mathrm{CON}$ groups in any exercise performance parameter at baseline.

Table 1 Characteristics of the participants previous to CRT implantation, presented by randomization groups performed a posteriori

\begin{tabular}{llll}
\hline & Unit & HIIT & CON \\
\hline Subjects & $(n)$ & 20 & 17 \\
Age & $($ years $)$ & $68 \pm 2$ & $67 \pm 2$ \\
Males & $(\%)$ & 76.5 & 75.0 \\
Etiology & $(\%)$ & & \\
$\quad$ Ischaemic & & 41.9 & 35.7 \\
$\quad$ Dilated cardiomyopathy & & 58.0 & 64.3 \\
Medication & $(\%)$ & & \\
$\quad$ Anticoagulant & & 73.1 & 76.5 \\
$\quad \beta$-Blockers & & 88 & 87.5 \\
ACE inhibitors & & 92.6 & 88.2 \\
Diuretics & & 96.3 & 88.2 \\
Sinus rhythm & $(\%)$ & 55.9 & 42.9 \\
QRS width & $(\mathrm{ms})$ & $150 \pm 4$ & $144 \pm 9$ \\
Body mass index & $\left(\mathrm{kg} / \mathrm{m}^{2}\right)$ & $26.3 \pm 1.0$ & $28.7 \pm 1.2$ \\
Heart rate & $(\mathrm{bpm})$ & $80.95 \pm 3.44$ & $78 \pm 4$ \\
Systolic blood pressure & $(\mathrm{mmHg})$ & $114 \pm 4$ & $121 \pm 4$ \\
Diastolic blood pressure & $(\mathrm{mmHg})$ & $63 \pm 2$ & $66 \pm 3$ \\
\hline
\end{tabular}

Values are expressed as mean \pm SEM

HIIT High-intensity interval training, $C R T$ cardiac resynchronization therapy, CON control
Table 2 Quality of life, functional class, exercise performance and echocardiographic parameters in HIIT and control CRT patients who met the per-protocol criteria

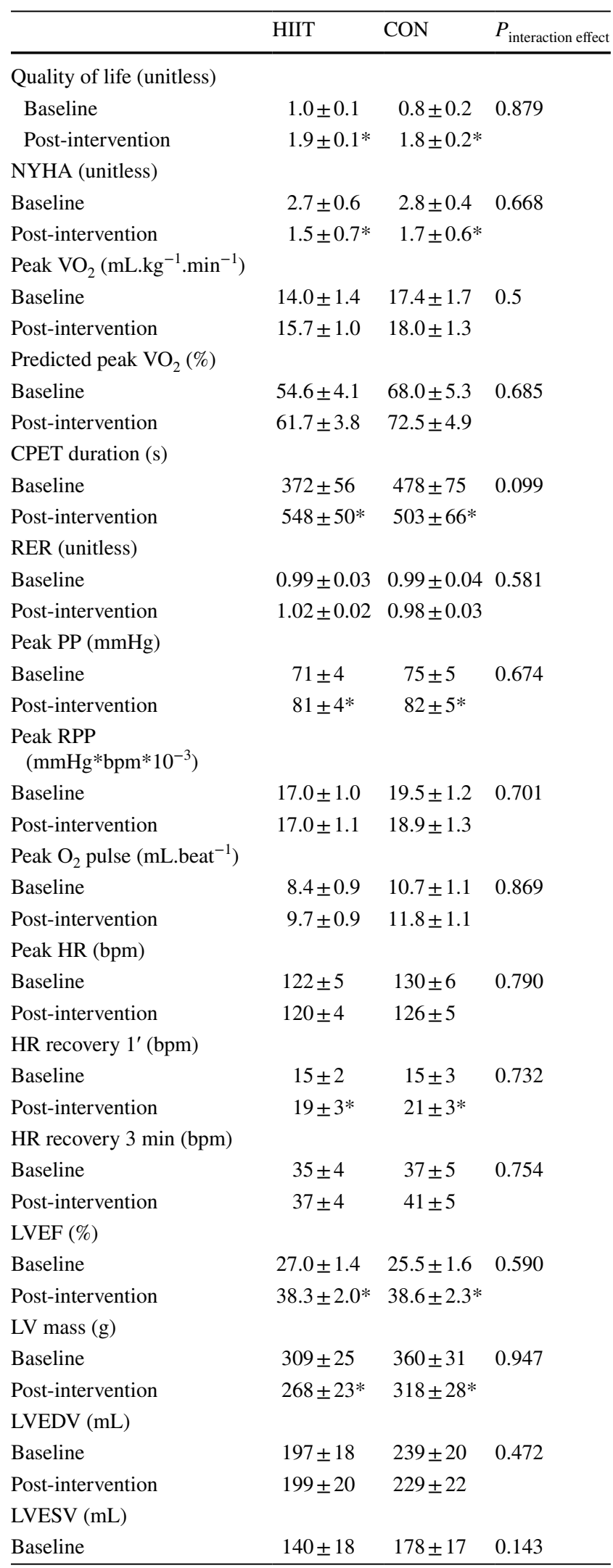


Table 2 (continued)

\begin{tabular}{lccc}
\hline & HIIT & CON & $P_{\text {interaction effect }}$ \\
\hline Post-intervention & $140 \pm 20$ & $149 \pm 19$ & \\
\hline
\end{tabular}

Values are expressed as mean $\pm \mathrm{SEM}$. *Significant time effects $(p<0.05)$

HIIT, high-intensity interval training; CRT, cardiac resynchronization therapy; CON, control; $\mathrm{P}$ change score, significance of differences between change scores (HIIT vs CON); NYHA, New York Heart Association Functional Class; Peak PP, pulse pressure at peak effort during cardiopulmonary exercise testing; Peak RPP, rate pressure product at peak effort during cardiopulmonary exercise testing; Peak HR, heart rate at peak effort during cardiopulmonary exercise testing; Peak VO2, oxygen consumption at peak effort during cardiopulmonary exercise testing; \%-predicted $\mathrm{VO}_{2}$, calculated according to normative values proposed by Wasserman et al. (2012); CPET duration, cardiopulmonary exercise testing duration; RER, respiratory exchange ratio; HR recovery $1 \mathrm{~min}$, heart rate recovery at $1 \mathrm{~min}$ after CPET; HR recovery $3 \mathrm{~min}$, Heart rate recovery at $3 \mathrm{~min}$ after CPET; LVEF, left

CPET duration increased in both groups (HIIT $=47.4 \%$, $\mathrm{CON}=5.1 \% ; p=0.008 ; \eta^{2}=0.205$; Fig. 2 ; Table 2). This improvement was neither coincident with an increase in peak $\mathrm{VO}_{2}\left(p=0.134 ; \eta^{2}=0.073\right)$ nor percent-predicted peak $\mathrm{VO}_{2}\left(p=0.07 ; \eta^{2}=0.109\right)$. However, in the intention-to-treat analysis we observed an interaction effect suggesting that CPET duration increased only in the HIIT group (25.9\%; $p=0.013 ; \eta^{2}=0.108$; Supplement 2$)$, and an increase in peak $\mathrm{VO}_{2}\left(\mathrm{HIIT}=8.6 \%, \mathrm{CON}=4.9 \% ; p=0.047 ; \eta^{2}=0.068\right)$ and percent-predicted peak $\mathrm{VO}_{2}(\mathrm{HIIT}=10.6 \%, \mathrm{CON}=4.3 \%$; $\left.p=0.05 ; \eta^{2}=0.081\right)$ in both groups.

Changes in CPET duration were associated with changes in peak $\mathrm{VO}_{2}$ (HIIT $r=0.595, p=0.006$; CON $r=0.727$, $p=0.007)$ and percent-predicted peak $\mathrm{VO}_{2}(\mathrm{HITT} r=0.582$, $p=0.007$; CON $r=0.681, p=0.015)$ in both analyses (Supplement 3). HR recovery at minute 1 increased in both groups $(\mathrm{HIIT}=32.3 \%, \mathrm{CON}=42.9 \% ; p=0.026$; $\eta^{2}=0.165$; Table 2) but not at minute 3 following CPET $\left(p=0.47 ; \eta^{2}=0.018\right) . \mathrm{O}_{2}$ pulse did not change in either group $\left(p=0.087 ; \eta^{2}=0.095\right)$.

Pulse pressure at peak effort increased similarly in both groups $\left(\mathrm{HIIT}=14.1 \%, \mathrm{CON}=9.5 \% ; p=0.01 ; \eta^{2}=0.176\right)$. The wider pulse pressure at peak effort in the HIIT group did not influence the myocardial workload at peak effort (Table 2). Similar results were observed in the intention-totreat analysis (Supplement 3).

\section{Echocardiographic parameters}

No significant differences were found between HIIT and CON groups in any echocardiographic parameter at baseline.

Increases in LVEF (HIIT $=42.2 \%$; $\mathrm{CON}=51.10 \%$; $\left.p<0.001 ; \eta^{2}=0.552\right)$ and decreases in LV mass $\left(\mathrm{HIIT}=13.26 \%, \mathrm{CON}=11.9 \% ; p=0.005 ; \eta^{2}=0.240\right)$ were

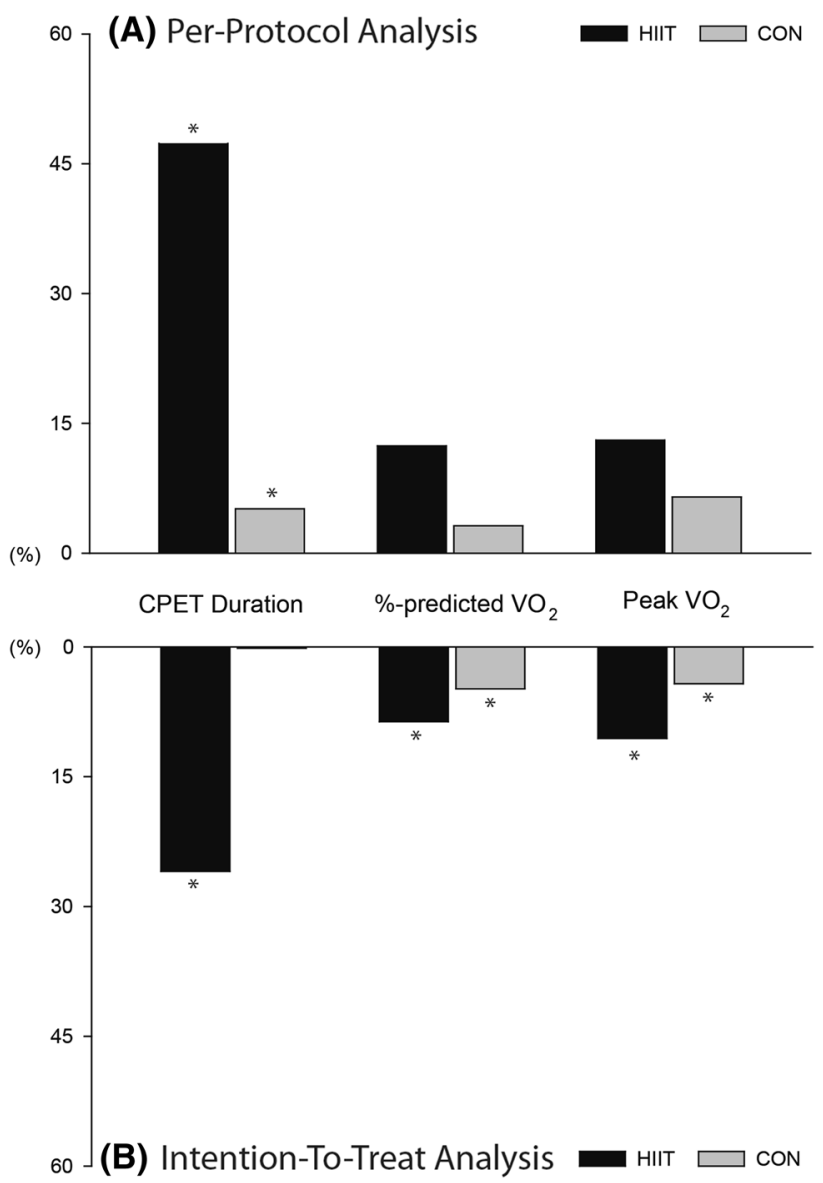

Fig. 2 Percentage changes on selected exercise performance parameters derived from the mixed designed two-way repeated measures ANOVA are presented for group with the per-protocol analysis and the intention-to-treat analysis. The graphs display absolute percentages (positive signs only); *Significant time effect $(p<0.05)$. HIIT High-intensity interval training, CON control, CPET duration cardiopulmonary exercise testing duration. \%-predicted $\mathrm{VO}_{2}$ calculated according to normative values proposed by Wasserman et al. (2012), Peak $\mathrm{VO}_{2}$ peak oxygen consumption during CPET

observed in both groups (Fig. 3; Table 2). Neither changes in LVEF nor LV mass were significantly associated with changes in exercise performance. LV volumes did not change significantly with time, and these results were similar when values were adjusted for body surface area (data not shown). However, LVESV decreased in both groups in the intention-to-treat analysis (HIIT $=5.1 \%, \mathrm{CON}=13.0 \%$; $p=0.021 ; \eta^{2}=0.093$; Supplement 2).

\section{Discussion}

The major findings of this study were that 6 months of HIIT in combination with CRT did not further improve indices of functional capacity and health-related quality of life, and LV structure and function, compared to CRT alone. However, 


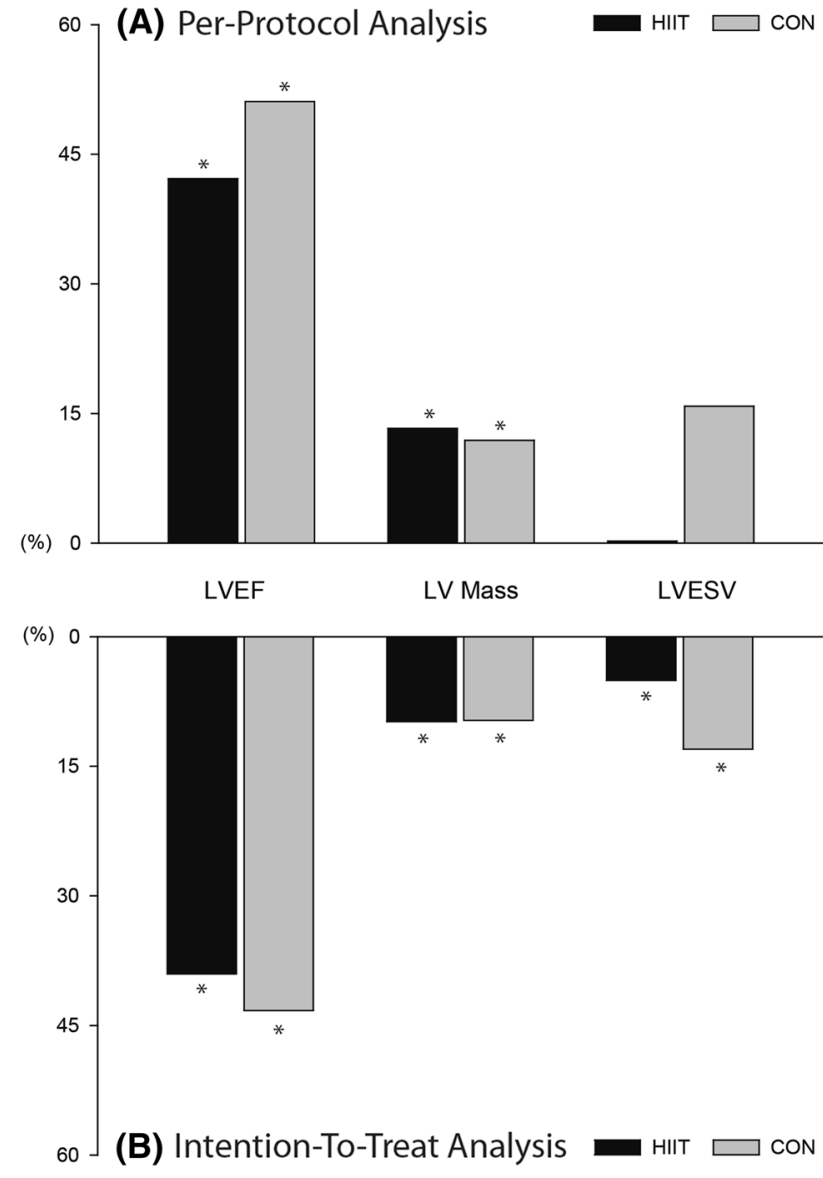

Fig. 3 Percentage changes on selected echocardiographic parameters derived from the mixed designed two-way repeated measures ANOVA are presented for group with the per-protocol analysis and the intention-to-treat analysis. The graphs display absolute percentages (positive signs only); *Significant time effect $(p<0.05)$. HIIT High-intensity interval training, CON control, $L V E F$ left ventricular ejection fraction, $L V$ mass left ventricular mass, $L V E S V$ left ventricular end-systolic volume

HIIT led to further improvements in exercise performance compared to CRT alone.

\section{Health-related quality of life and functional capacity}

The changes in health-related quality of life and NYHA class were similar between the two groups suggesting no additional benefits of HIIT following CRT. Thus, the effect of CRT itself was equally benefic without adding exercise training, even in changes in exercise tolerance and LVEF (Smolis-Bąk et al. 2015). However, previous literature shows that the improvements achieved may be maintained longer if patients continue exercising (Hussein and Thomas 2008).

Exercise capacity is usually improved following CRT (Auricchio et al. 2002) and a small number of studies have shown that exercise training following CRT produces further improvements (Patwala et al. 2009; Belardinelli et al. 2006; Smolis-Bąk et al. 2015; Conraads et al. 2007). Following 3-4 months of structured exercise training in patients in CRT, peak $\mathrm{VO}_{2}$ values, exercise duration and maximal workload achieved have been shown to increase (Patwala et al. 2009; Belardinelli et al. 2006; Smolis-Bak et al. 2015; Conraads et al. 2007). In general, improvements of $18-25 \%$ in peak $\mathrm{VO}_{2}$ and $18-34 \%$ in CPET duration have been reported with exercise in CHF patients (Downing and Balady 2011). In the present study, CPET duration increased up to $47.4 \%$ in HIIT in the per-protocol analysis, but the interaction effects were only significant in the intention-totreat analysis with increments of $25.9 \%$ in the HIIT group ( $\left.p=0.013 ; \eta^{2}=0.108\right)$. It is possible that adding HIIT to CRT improves walking performance and efficiency factors, contributing to positive effects on the economy of motion (Beneke and Meyer 1997) with expectable benefits in the performance of daily activities.

Another finding was the increase in peak pulse pressure observed in both groups. The rise in pressure from its diastolic to systolic value is determined by compliance of the aorta as well as ventricular stroke volume. Thus, we may theoretically assume an improvement in any of these throughout the study. Importantly, this occurred without significant changes in pulse pressure or LV volumes at rest, and without affecting myocardial oxygen uptake requirements.

\section{Echocardiographic parameters}

CRT reduces LV volumes, increases LV function (St John Sutton et al. 2003) and is strongly correlated with subsequent favorable clinical and arrhythmia outcomes (Kutyifa et al. 2013; Goldenberg et al. 2011). CRT is also associated with significant decreases in LV mass, septal and posterior wall thickness in mild and advanced CHF (St John Sutton et al. 2003; Kutyifa et al. 2013), indicative of LV structural reverse remodeling. Studies testing exercise as an adjuvant therapeutic to CRT also showed a decrease in LV volumes (Conraads et al. 2007; Smolis-Bąk et al. 2015; Belardinelli et al. 2006). However, this is not a universal finding and the percent changes in volumetric reverse remodeling are equivocal following CRT (St John Sutton et al. 2009; Patwala et al. 2009). Our analysis showed that no added benefits occurred in myocardial structure when HIIT was combined with CRT. Although this study was not designed to observe correlations between changes in LV volumes and LV mass, structural reverse remodeling following CRT has long been described as a late sequel of volumetric reverse remodeling (Zhang et al. 2006). However, that may not be the case in the present study. In the belief that changes in the structure and volume of the myocardium are parts of the same process, we can only infer that LV structural reverse remodeling in these patients was due to changes in interventricular septal and/or 
posterior wall thickness at end-diastole, reflecting a lower regional wall stress (Mannaerts 2006), and that LV volumetric and structural changes may not always coincide. The interaction of these variables is difficult to ascertain, especially when comparison studies have different time frames. Still, it is compatible with observations that benefits of CRT take time to materialize (Yu et al. 2002).

\section{Exercise training}

Most exercise training studies in patients with CHF employ moderate-to high-intensity exercise (70-80\% peak HR) (Downing and Balady 2011). We recognize that this exercise training program was more intense and longer than the usual cardiac rehabilitation offered to patients after myocardial infarction or coronary revascularization, and also when compared to more unconventional trials even in CRT. It is only during the last decade that HIIT has emerged, but it appears to be more advantageous in improving peak $\mathrm{VO}_{2}$ and ventricular remodeling parameters in patients with CHF (Guiraud et al. 2012). However, we and others showed that this is not a universal finding (Dimopoulos et al. 2006; Roditis et al. 2007; Iellamo et al. 2013; Ellingsen et al. 2017). There are no data yet regarding the adherence to HIIT in patients with CHF but, in coronary artery patients, the long-term adherence to HIIT has been shown to be superior- to moderate-intensity continuous exercise (Meyer et al. 2013), and to be perceived as a more enjoyable training modality in healthy adults (Bartlett et al. 2011). In our study, some patients felt that the 6-month HIIT protocol with active recovery was difficult to tolerate. HIIT prescription of $90-95 \%$ of maximal heart rate may be too high for some patients. As this appears to be associated with a reduced ability to complete exercise sessions due to fatigue and exhaustion, continuous aerobic training with the gradual inclusion of short-interval HIIT sessions using passive recovery may be more suitable for less fit or higher-risk patients with cardiac disease (Gayda et al. 2016). We and others (Ellingsen et al. 2017) suggest that exercise intensities should be regularly adapted to improvements in exercise capacity as well as worsening of symptoms or changes of medication. Repeated assessment of maximal heart rate and more emphasis on adjusting workload according to perceived level of effort might also be helpful. Therefore, a single exercise protocol is probably not suitable to all patients and should be individualized. Still, in patients with cardiac disease, who often report a lack of time as a reason for not exercising, HIIT may be considered a timeefficient substitute or alternative (or both) to traditional continuous aerobic training (Gayda et al. 2016).

\section{Limitations}

We did not mean to test the optimal timing to start exercise after CRT, or to compare intensities of exercise training. Therefore, this study should be carefully interpreted considering these and the following limitations. The per-protocol analysis tended to show superior benefits in the HIIT group, but these were only supported by significant interaction effects in the intention-to-treat analysis. This probably reflects the relatively small number of patients in each group and the wide standard deviations. Still, the intention-to-treat analysis provides an unbiased estimate of the efficacy of HIIT in patients in CRT.

The use of target HR zones is often not reliable in CHF due to frequent chronotropic incompetence, high prevalence of chronic atrial fibrillation, and constant occurrence of HR drift during exercise. As a result, exercise workloads corresponding to an individualized percentage of peak $\mathrm{VO}_{2}$ should be employed to prescribe HIIT intensity.

Additionally, cardiac function was assessed only at rest, just before CPET, and we did not evaluate cardiac function during exercise. This could have been interesting as the predictive ability of selected parameters may change during stress echocardiography.

Dropout was nearly $41 \%$ with HITT, slightly lower than results recorded in most European countries where the proportion of patients participating in post-hospital rehabilitation was below 50\% (Bjarnason-Wehrens et al. 2010). However, this may still have biased the results.

\section{Future directions}

It remains unclear whether HIIT benefits patients in CRT to a similar degree as more conventional forms of exercise training previously shown to maximize benefits in CRT (Patwala et al. 2009). HIIT in patients in CRT should be assessed in combination with other training regimes (inspiratory muscle training, resistance training), in different exercise allocations (hospital-based and telemonitoring guided homebased training) and different times from device implantation. It should also be examined with respect to intensity, duration of intervals and progression model.

\section{Conclusions and future directions}

Six months of HIIT in patients in CRT produced improvements in indices of functional capacity and health-related quality of life, exercise performance, and LV structure and function. However, HIIT only led to further improvements in exercise performance. 
Acknowledgements The authors would like to thank Dr. Neil Oldridge's suggestions on the manuscript. We would also acknowledge the contributions of the cardiopulmonary technicians and the medical interns in cardiology from Hospital Santa-Marta, and Mafalda Carinha from Faculdade de Motricidade Humana, Universidade de Lisboa.

Author contributions HSC, AA contributed to conception and design, critically revised the manuscript, and gave final approval. VS contributed to acquisition, analysis, critically revised the manuscript and gave final approval. XM contributed to acquisition, analysis, interpretation, drafted the manuscript and gave final approval. RP and BF contributed to interpretation, critically revised manuscript, and gave final approval. $\mathrm{PC}, \mathrm{MO}, \mathrm{MMC}$ contributed to acquisition, critically revised the manuscript, and gave final approval.

Funding This research was supported by National funding from the Portuguese Foundation for Science and Technology (PTDC/ DES/120249/2010)

\section{Compliance with ethical standards}

Conflict of interest The authors have no competing interests.

\section{References}

Abraham WT, Fisher WG, Smith AL, Delurgio DB, Leon AR, Loh E, Kocovic DZ, Packer M, Clavell AL, Hayes DL, Ellestad M, Trupp RJ, Underwood J, Pickering F, Truex C, McAtee P, Messenger J, Evaluation MSGMIRC (2002) Cardiac resynchronization in chronic heart failure. N Engl J Med 346(24):1845-1853. https:// doi.org/10.1056/NEJMoa013168

Auricchio A, Stellbrink C, Sack S, Block M, Vogt J, Bakker P, Huth C, Schondube F, Wolfhard U, Bocker D, Krahnefeld O, Kirkels H (2002) Long-term clinical effect of hemodynamically optimized cardiac resynchronization therapy in patients with heart failure and ventricular conduction delay. J Am Coll Cardiol 39(12):2026-2033

Bartlett JD, Close GL, MacLaren DP, Gregson W, Drust B, Morton JP (2011) High-intensity interval running is perceived to be more enjoyable than moderate-intensity continuous exercise: implications for exercise adherence. J Sports Sci 29(6):547-553. https:// doi.org/10.1080/02640414.2010.545427

Belardinelli R, Capestro F, Misiani A, Scipione P, Georgiou D (2006) Moderate exercise training improves functional capacity, quality of life, and endothelium-dependent vasodilation in chronic heart failure patients with implantable cardioverter defibrillators and cardiac resynchronization therapy. Eur J Cardiovasc Prev Rehabil 13(5):818-825

Beneke R, Meyer K (1997) Walking performance and economy in chronic heart failure patients pre and post exercise training. Eur $\mathrm{J}$ Appl Physiol Occup Physiol 75(3):246-251

Bjarnason-Wehrens B, McGee H, Zwisler AD, Piepoli MF, Benzer W, Schmid JP, Dendale P, Pogosova NG, Zdrenghea D, Niebauer J, Mendes M, Cardiac Rehabilitation Section European of Cardiovascular Prevention and Rehabilitation (2010) Cardiac rehabilitation in Europe: results from the European Cardiac Rehabilitation Inventory Survey. Eur J Cardiovasc Prev Rehabil 17(4):410-418. https://doi.org/10.1097/HJR.0b013e328334f42d

Brignole M, Auricchio A, Baron-Esquivias G, Bordachar P, Boriani G, Breithardt OA, Cleland J, Deharo JC, Delgado V, Elliott PM, Gorenek B, Israel CW, Leclercq C, Linde C, Mont L, Padeletti L, Sutton R, Vardas PE (ESC) ESoC (EHRA) EHRA (2013)
2013 ESC guidelines on cardiac pacing and cardiac resynchronization therapy: the task force on cardiac pacing and resynchronization therapy of the European Society of Cardiology (ESC). Developed in collaboration with the European Heart Rhythm Association (EHRA). Europace 15(8):1070-1118. https ://doi.org/10.1093/europace/eut206

Cleland JGF, Daubert J, Erdmann E, Freemantle N, Gras D, Kappenberger L, Tavazzi L, Cardiac Resynchronization-Heart Failure (CARE-HF) Study Investigators (2005) The effect of cardiac resynchronization on morbidity and mortality in heart failure. N Engl J Med 352(15):1539-1549

Conraads VM, Vanderheyden M, Paelinck B, Verstreken S, Blankoff I, Miljoen H, De Sutter J, Beckers P (2007) The effect of endurance training on exercise capacity following cardiac resynchronization therapy in chronic heart failure patients: a pilot trial. Eur J Cardiovasc Prev Rehabil 14(1):99-106

Devereux RB, Alonso DR, Lutas EM, Gottlieb GJ, Campo E, Sachs I, Reichek N (1986) Echocardiographic assessment of left ventricular hypertrophy: comparison to necropsy findings. Am J Cardiol 57(6):450-458

Dimopoulos S, Anastasiou-Nana M, Sakellariou D, Drakos S, Kapsimalakou S, Maroulidis G, Roditis P, Papazachou O, Vogiatzis I, Roussos C, Nanas S (2006) Effects of exercise rehabilitation program on heart rate recovery in patients with chronic heart failure. Eur J Cardiovasc Prev Rehabil 13(1):67-73

Downing J, Balady GJ (2011) The role of exercise training in heart failure. J Am Coll Cardiol 58(6):561-569

Ellingsen $\varnothing$, Halle M, Conraads V, Støylen A, Dalen H, Delagardelle C, Larsen AI, Hole T, Mezzani A, Van Craenenbroeck EM, Videm V, Beckers P, Christle JW, Winzer E, Mangner N, Woitek F, Höllriegel R, Pressler A, Monk-Hansen T, Snoer M, Feiereisen P, Valborgland T, Kjekshus J, Hambrecht R, Gielen S, Karlsen T, Prescott E, Linke A, SMARTEX Heart Failure Study (Study of Myocardial Recovery After Exercise Training in Heart Failure) Group (2017) High-intensity interval training in patients with heart failure with reduced ejection fraction. Circulation 135(9):839-849. https://doi.org/10.1161/circulatio naha.116.022924

Evangelista A, Flachskampf F, Lancellotti P, Badano L, Aguilar R, Monaghan M, Zamorano J, Nihoyannopoulos P, Echocardiography EAo (2008) European Association of Echocardiography recommendations for standardization of performance, digital storage and reporting of echocardiographic studies. Eur J Echocardiogr 9(4):438-448. https://doi.org/10.1093/ejechocard /jen174

Gayda M, Ribeiro PA, Juneau M, Nigam A (2016) Comparison of different forms of exercise training in patients with cardiac disease: where does high-intensity interval training fit? Can J Cardiol 32(4):485-494. https://doi.org/10.1016/j.cjca.2016.01.017

Goldenberg I, Moss AJ, Hall WJ, Foster E, Goldberger JJ, Santucci P, Shinn T, Solomon S, Steinberg JS, Wilber D, Barsheshet A, McNitt S, Zareba W, Klein H, Executive Committee MADITCRT (2011) Predictors of response to cardiac resynchronization therapy in the Multicenter Automatic Defibrillator Implantation Trial with Cardiac Resynchronization Therapy (MADIT-CRT). Circulation 124(14):1527-1536. https://doi.org/10.1161/CIRCU LATIONAHA.110.014324

Grewal J, McCully RB, Kane GC, Lam C, Pellikka PA (2009) Left ventricular function and exercise capacity. JAMA 301(3):286-294. https://doi.org/10.1001/jama.2008.1022

Guiraud T, Nigam A, Gremeaux V, Meyer P, Juneau M, Bosquet L (2012) High-intensity interval training in cardiac rehabilitation. Sports Med 42(7):587-605. https://doi.org/10.2165/11631910000000000-00000

Hambrecht R, Gielen S, Linke A, Fiehn E, Yu J, Walther C, Schoene N, Schuler G (2000) Effects of exercise training on left 
ventricular function and peripheral resistance in patients with chronic heart failure: a randomized trial. JAMA 283(23):3095-3101

Hussein NA, Thomas MA (2008) Rehabilitation of patients with implantable cardioverter/defibrillator: a literature review. Acta Cardiol 63(2):249-257. https://doi.org/10.2143/AC.63.2.20295 35

Iellamo F, Manzi V, Caminiti G, Vitale C, Castagna C, Massaro M, Franchini A, Rosano G, Volterrani M (2013) Matched dose interval and continuous exercise training induce similar cardiorespiratory and metabolic adaptations in patients with heart failure. Int $\mathbf{J}$ Cardiol 167(6):2561-2565. https://doi. org/10.1016/j.ijcard.2012.06.057

Keteyian SJ, Piña IL, Hibner BA, Fleg JL (2010) Clinical role of exercise training in the management of patients with chronic heart failure. J Cardiopulm Rehabil Prev 30(2):67-76. https:// doi.org/10.1097/HCR.0b013e3181d0c1c1

Kutyifa V, Solomon SD, Bourgoun M, Shah AM, Pouleur AC, Knappe D, McNitt S, Wang PJ, Merkely B, Pfeffer M, Moss AJ, Zareba W (2013) Effects of cardiac resynchronization therapy on left ventricular mass and wall thickness in mild heart failure patients in MADIT-CRT. Heart Rhythm 10(3):354-360. https ://doi.org/10.1016/j.hrthm.2012.11.007

Lang RM, Badano LP, Mor-Avi V, Afilalo J, Armstrong A, Ernande L, Flachskampf FA, Foster E, Goldstein SA, Kuznetsova T, Lancellotti P, Muraru D, Picard MH, Rietzschel ER, Rudski L, Spencer KT, Tsang W, Voigt JU (2015) Recommendations for cardiac chamber quantification by echocardiography in adults: an update from the American Society of Echocardiography and the European Association of Cardiovascular Imaging. Eur Heart J Cardiovasc Imaging 16(3):233-270. https://doi.org/10.1093/ ehjci/jev014

Mannaerts H (2006) Regression of left ventricular mass and wall thickness after cardiac resynchronization therapy: proof of pathophysiological concept. Eur Heart J 27(12):1392-1393. https://doi.org/10.1093/eurheartj/eh1048

Meyer P, Gayda M, Juneau M, Nigam A (2013) High-intensity aerobic interval exercise in chronic heart failure. Curr Heart Fail Rep 10(2):130-138. https://doi.org/10.1007/s11897-013-0130-3

Oldridge N, Höfer S, McGee H, Conroy R, Doyle F, Saner H (2014) The HeartQoL: part II. Validation of a new core healthrelated quality of life questionnaire for patients with ischemic heart disease. Eur J Prev Cardiol 21(1):98-106. https://doi. org/10.1177/2047487312450545

Patwala AY, Woods PR, Sharp L, Goldspink DF, Tan LB, Wright DJ (2009) Maximizing patient benefit from cardiac resynchronization therapy with the addition of structured exercise training: a randomized controlled study. J Am Coll Cardiol 53(25):2332-2339

Ponikowski P, Voors AA, Anker SD, Bueno H, Cleland JG, Coats AJ, Falk V, González-Juanatey JR, Harjola VP, Jankowska EA, Jessup M, Linde C, Nihoyannopoulos P, Parissis JT, Pieske B, Riley JP, Rosano GM, Ruilope LM, Ruschitzka F, Rutten FH, van der Meer P, Members ATF (2016) 2016 ESC Guidelines for the diagnosis and treatment of acute and chronic heart failure: the Task Force for the diagnosis and treatment of acute and chronic heart failure of the European Society of Cardiology (ESC)Developed with the special contribution of the Heart Failure Association (HFA) of the ESC. Eur Heart J 37(27):2129_ 2200. https://doi.org/10.1093/eurheartj/ehw128

Roditis P, Dimopoulos S, Sakellariou D, Sarafoglou S, Kaldara E, Venetsanakos J, Vogiatzis J, Anastasiou-Nana M, Roussos C, Nanas S (2007) The effects of exercise training on the kinetics of oxygen uptake in patients with chronic heart failure. Eur J Cardiovasc Prev Rehabil 14(2):304-311. https://doi. org/10.1097/HJR.0b013e32808621a3
Santos V, Abreu A, Pinto R, Melo X, Cunha P, Oliveira M, Selas M, Soares R, Ferreira R, Sardinha LB, Fernhall B (2015) Effect of high intensity interval training on cardiac remodeling following cardiac resynchronization therapy: RCT. Med Sci Sports Exerc. https://doi.org/10.1249/01.mss.0000477584.48099.97

Schiller NB, Shah PM, Crawford M, DeMaria A, Devereux R, Feigenbaum H, Gutgesell H, Reichek N, Sahn D, Schnittger I (1989) Recommendations for quantitation of the left ventricle by two-dimensional echocardiography. American Society of Echocardiography Committee on Standards, Subcommittee on Quantitation of Two-Dimensional Echocardiograms. J Am Soc Echocardiogr 2(5):358-367

Smolis-Bąk E, Dąbrowski R, Piotrowicz E, Chwyczko T, Dobraszkiewicz-Wasilewska B, Kowalik I, Kazimierska B, Jędrzejczyk B, Smolis R, Gepner K, Maciąg A, Sterliński M, Szwed H (2015) Hospital-based and telemonitoring guided home-based training programs: effects on exercise tolerance and quality of life in patients with heart failure (NYHA class III) and cardiac resynchronization therapy. A randomized, prospective observation. Int J Cardiol 199:442-447. https://doi.org/10.1016/j.ijcar d.2015.07.041

St John Sutton MG, Plappert T, Abraham WT, Smith AL, DeLurgio DB, Leon AR, Loh E, Kocovic DZ, Fisher WG, Ellestad M, Messenger J, Kruger K, Hilpisch KE, Hill MR, Multicenter InSync Randomized Clinical Evaluation (MIRACLE) Study Group (2003) Effect of cardiac resynchronization therapy on left ventricular size and function in chronic heart failure. Circulation 107(15):1985-1990. https://doi.org/10.1161/01.cir.00000 65226.24159.e9

St John Sutton M, Ghio S, Plappert T, Tavazzi L, Scelsi L, Daubert C, Abraham WT, Gold MR, Hassager C, Herre JM, Linde C, Group RrRiSlvdRS (2009) Cardiac resynchronization induces major structural and functional reverse remodeling in patients with New York Heart Association class I/II heart failure. Circulation 120(19):1858-1865. https://doi.org/10.1161/circulatio naha.108.818724

Wasserman K, Hansen J, Sue D, Stringer W, Sietsema K, Sun X-G, Whipp B (2012) Principles of exercise testing and interpretation. Normal values, 5th edn. Lippincott Williams \& Wilkins, Philadelphia

Weston KS, Wisløff U, Coombes JS (2014) High-intensity interval training in patients with lifestyle-induced cardiometabolic disease: a systematic review and meta-analysis. $\mathrm{Br} \mathrm{J}$ Sports Med 48(16):1227-1234. https://doi.org/10.1136/bjsports-2013092576

Wisloff U, Stoylen A, Loennechen JP, Bruvold M, Rognmo O, Haram PM, Tjonna AE, Helgerud J, Slordahl SA, Lee SJ, Videm V, Bye A, Smith GL, Najjar SM, Ellingsen O, Skjaerpe T (2007) Superior cardiovascular effect of aerobic interval training versus moderate continuous training in heart failure patients: a randomized study. Circulation 115(24):3086-3094. https://doi. org/10.1161/CIRCULATIONAHA.106.675041

Wisløff U, Ellingsen $\varnothing$, Kemi OJ (2009) High-intensity interval training to maximize cardiac benefits of exercise training? Exerc Sport Sci Rev 37(3):139-146. https://doi.org/10.1097/ JES.0b013e3181aa65fc

Yu CM, Chau E, Sanderson JE, Fan K, Tang MO, Fung WH, Lin H, Kong SL, Lam YM, Hill MR, Lau CP (2002) Tissue Doppler echocardiographic evidence of reverse remodeling and improved synchronicity by simultaneously delaying regional contraction after biventricular pacing therapy in heart failure. Circulation 105(4):438-445

Zeitler EP, Piccini JP, Hellkamp AS, Whellan DJ, Jackson KP, Ellis SJ, Kraus WE, Keteyian SJ, Kitzman DW, Ewald GA, Fleg JL, Piña IL, O'Connor CM, Investigators H-A (2015) Exercise training and pacing status in patients with heart failure: 
results from HF-ACTION. J Card Fail 21(1):60-67. https://doi. org/10.1016/j.cardfail.2014.10.004

Zhang Q, Fung JW, Auricchio A, Chan JY, Kum LC, Wu LW, Yu CM (2006) Differential change in left ventricular mass and regional wall thickness after cardiac resynchronization therapy for heart failure. Eur Heart J 27(12):1423-1430. https://doi.org/10.1093/ eurheartj/ehi885
Publisher's Note Springer Nature remains neutral with regard to jurisdictional claims in published maps and institutional affiliations. 